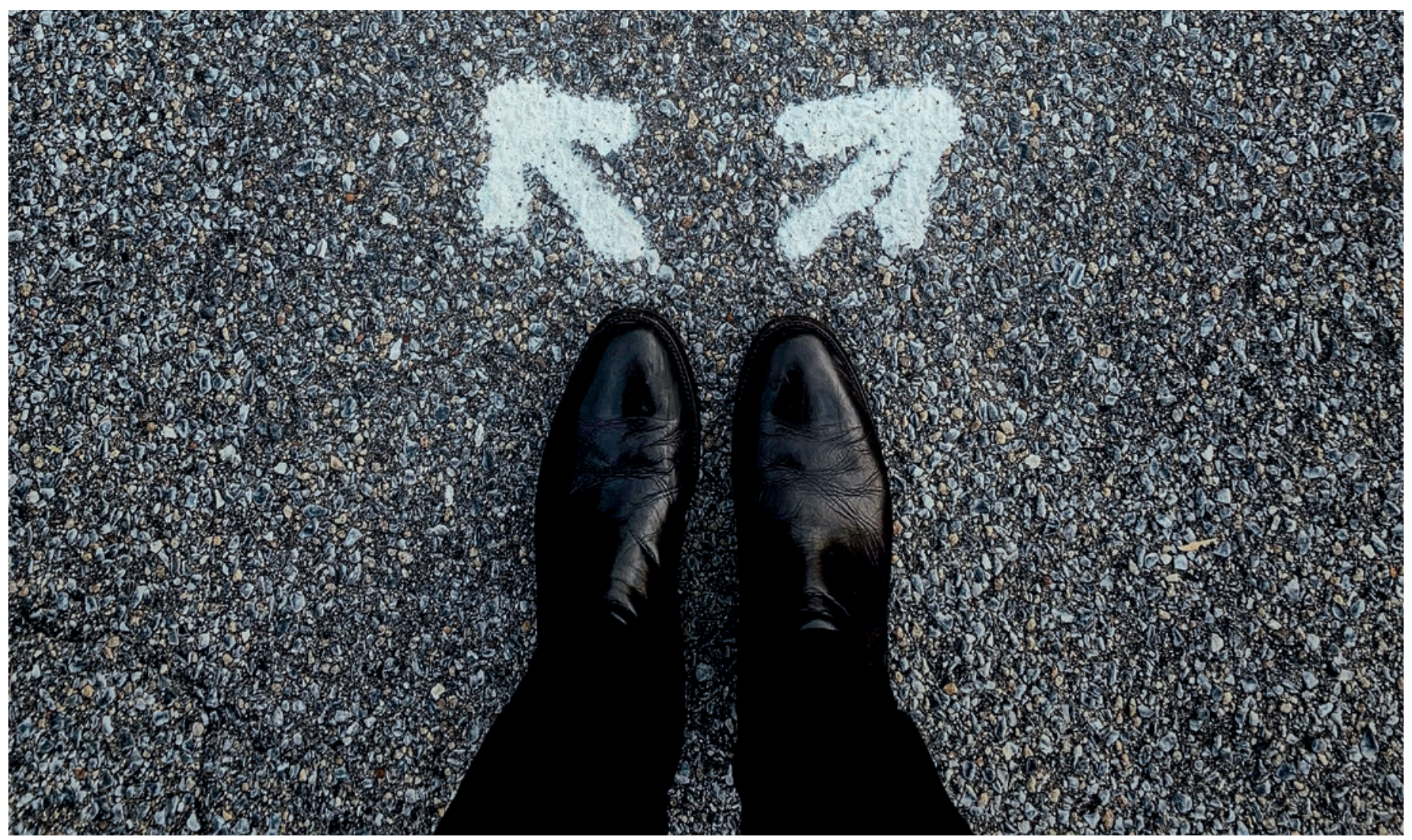

\title{
Le choix et le hasard
}

\section{Julia Vecsey}

Dr méd., membre de la FMH

Ces deux histoires commencent un matin, au saut du lit. Le hasard choisit alors pour nous: va-t-on se lever du pied gauche ou du droit? Et de ce choix va dépendre le déroulement de toute la journée, que dis-je, de toute la vie!

\section{Du côté face}

\section{Premier épisode}

Pied gauche: Par un matin pluvieux, le réveille-matin de Juliette ne sonna pas à sept heures tapantes comme prévu, mais heureusement, cette mésaventure lui étant déjà arrivée, elle avait mis en place un réveil de secours, qui, lui, sonna à 7 h10. Elle se redressa, prête à sauter du lit, lorsqu'un vertige lui tourna la tête. Prudemment, elle attendit que cela cesse et mit le pied gauche au sol. Elle tâta le sol à la recherche de ses pantoufles, et ne les trouvant pas, voulut poursuivre son chemin pieds nus; grand mal lui en prit, car elle glissa dans le couloir, tenta de se retenir au premier meuble venu, qui malheureusement se trouvait être une bibliothèque chargée de livres, qui n'attendirent pas une seconde pour se précipiter à terre. Juliette perdit encore quelques minutes à essayer de rassembler tant bien que mal les ouvrages, puis se fit un café, dans lequel elle mit distraitement deux grandes cuillères de... sel!

Pied droit: le même matin, le radioréveil de Jules s'enclencha et diffusa une musique douce; le premier rayon d'un soleil chaleureux se fraya un chemin entre les nuages. Jules posa le pied droit par terre, rencontra sa pantoufle avec bonheur et, après s'être rasé de près, dégusta un thé savoureux, juste bien sucré.

\section{Deuxième épisode}

Juliette descendit dans la rue, chercha longuement à retrouver sa voiture, garée dans les parages, mais allez savoir où? Après quelques investigations, elle la vit, 
retrouva avec difficulté ses clés au fond de son sac encombré d'un indescriptible fourbi féminin, et une fois qu'elle eût mit la main dessus, elle eut la désagréable surprise de rencontrer une résistance dans la serrure, et Juliette ne réussit par tous ses efforts qu'à casser cette dernière! Il fallut attendre le dépanneur, ce qui la retarda encore.

Jules, quant à lui, enfourcha son vélo, gonflé à souhait, et se rendit sans encombre sur son lieu de travail, le Centre Européen d'Etudes Spatiales.

\section{Troisième épisode}

Juliette arriva à son atelier de couture avec du retard, ce qui n'était pas très grave, car en ces temps troublés, les commandes se faisaient rares, l'endroit était donc désert. Elle était en train de confectionner une paire de gants, lorsqu'elle se rendit compte qu'elle avait cousu le pouce gauche sur la main droite... Elle en fut toute retournée.

Les projets de Jules étaient quant à eux bien plus ambitieux: il participait à un programme de "voirie de l'espace», avec le projet d'envoyer dans le ciel étoilé un véhicule capable de rassembler et désintégrer les débris d'engins spatiaux encombrants.

\section{Quatrième épisode}

A la pause de midi, Juliette décida de se rendre au café des Amis, le restaurant voisin, qui servait un plat du jour savoureux. Elle s'installa seule à une table près de la porte d'entrée.

Au même moment, Jules décida lui aussi de se rendre au Café des Amis pour déjeuner. En chemin, il sifflotait gaiement, frappant de son pied droit et avec énergie dans les petits cailloux qui se trouvaient sur sa route. Il voulait rejoindre un groupe de collègues attablés au fond de la salle.

Il passa devant Juliette, évita soigneusement le pied gauche de la jeune femme qui dépassait de la table et qui risquait de faire trébucher les passants, mais il ne la remarqua pas.

\section{Cinquième épisode}

Après leur dure journée de labeur, chacun regagna son domicile. Ils décidèrent chacun de leur côté de se mettre dans une tenue négligée mais étudiée, avant de ressortir pour aller dans une boîte de nuit branchée. Après s'être déhanchés comme des fous sur la piste de danse, ils allèrent jusqu'au bar pour se désaltérer, et ils se retrouvèrent côte à côte, le pied gauche de Juliette frôlant le pied droit de Jules.

Puis, par la magie des ondes pédestres, les pieds se reconnurent, réalisèrent qu'ils s'étaient déjà rencontrés plus tôt dans la journée, alors que les têtes l'ignoraient encore. Jules et Juliette engagèrent la conversation et constatèrent qu'ils travaillaient tous les deux dans le même quartier et qu'ils pourraient facilement se revoir, ce dont tous deux avaient envie.

A vous d'imaginer la suite de cette histoire qui tourne résolument en histoire d'amour...

\section{Du côté pile, tout se passe à l'envers}

\section{Premier épisode}

C'est Juliette qui se lève du pied droit, qui retrouve aisément sa voiture, se précipite dans son d'atelier de couture, pour découvrir qu'elle croule sous les commandes. Jules de son côté se lève du pied gauche, trouve son vélo avec un pneu crevé, en conséquence, il arrive tardivement sur son lieu de travail pour constater que son projet de poubelle de l'espace ne peut pas fonctionner sans une fine pellicule textile servant de filtre. Il retourne le problème dans tous les sens, mais ne sait pas comment le résoudre.

\section{Deuxième épisode}

$\mathrm{Au}$ repas de midi, au café des Amis, il trébuche sur le pied droit de Juliette, tombe, casse ses lunettes, mais fait ainsi connaissance avec la jeune femme; elle l'invite à sa table, ils discutent et il réalise qu'elle pourrait lui apporter la confection de la pellicule tant recherchée.

\section{Episodes suivants et épilogue}

Ils vont désormais travailler ensemble, et concrétiser le projet de poubelle de l'espace grâce à leur contribution mutuelle, et leur découverte du... philtre!

Là aussi, je vous laisse imaginer la suite de la rencontre... Et bien sûr, ils vécurent heureux et eurent un certain nombre d'enfants!

Il n'y a pas de moralité à cette histoire, nous avons seulement la preuve que ce qui devait arriver arrive toujours, quel que soit le pied du lever...

Crédits photo

Jon Tyson / Unsplash 